\title{
What Difference Does Diversity Make in Managing Student Employees?
}

\section{Jane McGurn Kathman and Michael D. Kathman}

\begin{abstract}
Most campuses in this country have made a commitment to increase the diversity of their student population. This presents opportunities and challenges for library staff as they supervise a more diverse group of student employees. The opportunities include employees who can serve as sources of information and who can contribute their perspectives about what might make the library more inclusive in the types of services it offers. The challenges are that library staff must rethink the way they select, train, supervise, and evaluate a more diverse work force. This article suggests some of the methods to adapt each of these dimensions of management as student employee diversity increases.
\end{abstract}

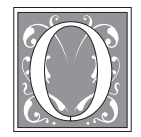

ver the past decade, the nation's campuses have made a commitment to increase the diversity of their faculty, staff, and student populations. Such a commitment is not surprising given the change in demographics that has and will continue to occur. Because libraries often are the largest employers of student staff on campus, the composition of library student employees should be changing along with that of the student body. What implications does this have for the management of the student work force?

First, the definition of diversity must be clear. "Cultural diversity, as the expression is intended to be understood today, has a relatively short history. One of the most striking characteristics of the discourse of diversity is its tendency to evade definition. In the past the meanings signified by 'cultural diversity' were cast in such terms as affirmative action, minorities, third world, racial identity, ethnic studies, and several other phrases." ${ }^{1}$ For the authors, diversity means any change in the dominant culture that has prevailed in any particular library. This can include changes in employee ethnicity, race, sexual orientation, age, abilities/disabilities, and/or religious preference. In addition, diversity in the workplace encompasses both international and domestic cultures.

Working within this diverse landscape challenges some of our preexisting knowledge, assumptions, and methods of doing things. As Darlene M. Ziolkowski states, managing diversity is both simple and complex: 
Simple in that adherence to sound management principles and respect for individuality can serve to resolve some issues. Complex in that managing a diverse workforce means taking into account the fact that individuals view things and handle things in different ways. Complex also in that what is being called for in many cases is change in management style and change in long held attitudes, and change, by its very nature, can bring uneasiness and tension. ${ }^{2}$

R. Roosevelt Thomas Jr. argues that managing diversity is not the same as either affirmative action or the valuing differences approach. Instead, managing diversity is a "way of thinking toward the objective of creating an environment that will enable all employees to reach their full potential in pursuit of organizational objectives . . . . Consider a jar of red jelly beans into which you place yellow and green jelly beans. Everyday language labels the yellow and green beans as 'diversity,' but managing diversity views the mixture of yellow, green, and red jelly beans to be 'diversity.' It recognizes further that the beans can differ in ways other than color; such as taste, age, weight, and time in the jar. Even among all red beans there can be substantial diversity." ${ }^{3}$

One of the most difficult issues to deal with in managing diversity is to answer the questions: How much should "they" change? How much should I "accept" what they do?

Although there are no definitive answers to these questions, there are possible hints/guidelines. For example, international students come to American institutions for a variety of reasons. Some simply want an American education. Others want to be able to understand how Americans think and work so that they can return home and work with international companies. And still others plan to emigrate to, or at least work in, this country for a significant time period. As managers get to know their student employees, they might begin to learn where each individual fits.

Students with disabilities, either physical or learning, must be accommodated legally. The same can be said about American students from different cultural backgrounds; they cannot and should not be discriminated against. Even if it were not a legal issue, libraries cannot afford to lose the talents these people can bring to their work force.

How much change is needed is dictated in part by law and to a great extent by common sense. As managers get to know their student employees, they will be able to better identify what the students' needs are and how they can adjust together for mutual benefit. Because many institutions tend to recruit international students from particular countries and often develop special programs for different cultural backgrounds and/or special programs for specific disabilities, it is possible and important for libraries to develop student employment programs around the needs of an identified diversity.

\section{Students with disabilities, either physical or learning, must be accommodated legally.}

Members of a diverse student work force can be hired for "normal" student employee jobs, but minority students also may be hired to teach other minority students how to use the library. As the library recruits a more diverse student body, many of these students have not had the same training and library access as the majority students. Selecting and training minority students to assist their peers will lighten the training load on the full-time staff. Perhaps more important, peer training has proved to be a very effective way to assist students from different backgrounds. The need for and success of such 
programs has been widely reported in the literature..$^{4-6}$

Why should supervising a diverse set of student employees be any different from supervising a homogeneous group of students? In her article "Supervising a Diverse Staff," Barbara MacAdam presents an inventory of issues that members of the library staff may encounter, including:

- Differing background, values, and experiences may create roadblocks to a shared sense of community.

- Diverse language backgrounds, communication styles, and learning modes may mean new methods are needed for communication, orientation, and training.

- Implicit rules of conduct and behavior often taken for granted may not be obvious to multicultural students.

- Conducting performance evaluations and resolving conflict may need new models.

- Some staff members may feel less valued than in the past. ${ }^{7}$

Following are some suggestions and recommendations to assist library staff in dealing with these and other issues that arise as libraries move to a more diverse student work force.

\section{Selecting and Hiring a Diverse Student Staff}

It is the authors' belief that libraries should take a proactive approach and actively recruit a student employee group that mirrors the composition of the larger student body. A good starting point is to create a liaison with both the admissions office and the student employment office. The admissions office can provide the background data and a diversity profile of incoming and current students. The student personnel office needs to know of the library's interest and may assist in the recruiting effort. Each campus has unique structures in place to deal with various members of the diverse student population. The library should identify any other offices (i.e., minority, international, or advising) that may be of assistance in its selection and hiring process.

When dealing with a more diverse applicant pool, a few adjustments may need to be made in the selection process, beginning with the job description. The Americans with Disabilities Act of 1990 does not require employers to revise job descriptions, but libraries need to clearly state the essential functions of any jobs that student employees are hired to perform. 8 When describing the requirements of the jobs available, any physical requirements such as heavy lifting or standing for long periods of time should be considered. Similarly, for international students, what are the English-language skills required to perform the job effectively?

In the selection process, it is important

\section{Each campus has unique structures in place to deal with various members of the diverse student population.}

to be open to the talents that individuals with diverse backgrounds can bring to the workplace; both job descriptions and interview questions should focus on only the essential requirements of the job. As Jim Kennedy and Anna Everest express it:

\begin{abstract}
As managers, however, when we look for a quality such as assertiveness in an employee, we really need to examine whether this characteristic provides the opportunity to accomplish the objectives of the position. Perhaps such qualities as persistence or attention to detail can help achieve the desired end result. If we can avoid a narrow definition of required qualities, we can be more inclusive of people from other cultures. ${ }^{9}$
\end{abstract}

Interview questions should be designed to elicit information that allows the best fit between the library, the student, and the job. A student struggling with 
English probably is not best suited for a public service area but may be very skilled in computer usage or shelving books. The only questions appropriate to ask are those that relate specifically to how the potential student worker will be able to perform the duties of the job. Behavioral interviewing is an excellent way to interview individuals with known disabilities. This technique utilizes interview questions based on past behavior as a predictor of future behavior. For example: "We need to pay great attention to detail and accuracy. Tell me how you performed a similar task in a past employment situation."10

Sondra Thiederman suggests the following tips for employment applications and interviews to assist in assessing the culturally different applicant:

1. Do not prejudge a worker according to his or her ethnic background, name, or accent.

2. Do not draw rash conclusions from a gentle handshake, direct or indirect eye contact, or any other behavior related to cultural style.

3. Conduct the interview in private.

4. If culturally appropriate, allow workers to praise themselves in writing.

5. Examine physical evidence of past accomplishments, supply the applicant with a job-related problem to solve, and check references rather than insist on the worker's praising him- or herself.

6. Ask the applicant or employee what coworkers would say about his or her work.

7. Ask a series of questions in order to learn of past accomplishments.

8. Ask that the applicant complete the application in the office and alone as a means of checking English-language reading and writing skills.

9. Assess English-language reading skills by including some lengthy instructions on the employment application.

10. Assess English-language writing skills by asking for a short essay on the employment application.
11. Assess how much the worker speaks and understands English by involving him or her in a lengthy conversation. ${ }^{11}$

Any student employee supervisor who decides to use any of these suggestions should make certain that all applicants are treated the same during the hiring phase. For example, if it is deemed necessary to check English-language ability by having the prospective employee fill out the application in the office, all applicants must be required to do so.

\section{Diversity and Orientation}

Orientation is the first opportunity to formally convey the library's commitment to a diverse work force. College graduates will enter a full-time workplace with diversity as the norm; therefore, student employee supervisors play an important part in students' preparation for the future. Diversity should be presented as a valuable and important part of the library's mission, which includes an accepting and tolerant work environment. "This may be the first time in the life of the student that this emphasis is presented, especially as a value and standard of work behavior. This includes diversity in respect to culture, race, gender and physical ability."12

Ziolkowski emphasized that the orientation process should include a review of institutional human rights policies, many of which stem from the law. "Be sure that the policies stressing laws and regulations guarding the dignity and respect of individual personhood are covered (i.e., discrimination, affirmative action, sexual harassment policies, protection against a hostile work environment, the Americans with Disability Act, etc.). International students as well as other students from diverse cultural backgrounds need a thorough orientation to legal policies and practices in these areas in order to function successfully."13 Including legal policies in the orientation is often overlooked. This could prevent problems in the future 
because in most institutions, the same laws and policies for any other employee on campus cover student employees. The written institutional policies, or reference to them, should be included in any student employee handbook.

\section{With a diverse work force, special care needs to be taken to present expected work behavior and norms.}

With a diverse work force, special care needs to be taken to present expected work behavior and norms. For many students, this is the first employment experience in a professional setting. Those coming from different cultures may have quite different expectations about employee standards and rituals. If student supervisors are not clear on "how things work," the result can be poor performance and conflict. In light of the many unwritten rules of operation within the library or its units, it is unfair to assume that student employees outside the dominant culture will recognize or understand what is important. It may be necessary to explain:

- what a timecard is and what it means to the student;

- the importance of getting to work on time;

- how people dress for work;

- that questions and suggestions are expected and encouraged.

As Gary Althen states it in "Cultural Differences on Campus,"

American supervisors assume that a 'good' employee is one who does the following things:

- Arrives at work on time, or, if lateness is unavoidable, gives a timely notice about the anticipated lateness

- Follows instructions, and asks for clarification whenever instructions are unclear

- Considers it more important to 'get the job done' than to develop and maintain social relationships with coworkers and clients

- Takes the initiative to do related work that clearly needs to be done, and to make suggestions that might lead to improvement in the operation

- Treats coworkers and clients respectfully, whatever their social status and gender

- Behaves rather informally, 'chatting' in a 'friendly' way with colleagues, and perhaps(depending upon the situation) with clients too

- Works at least as hard as others do. ${ }^{14}$

Many cultures do not have the same sense of time the American culture has, nor do they have the same view of how men and women relate or of how the individual relates to the group. Thus, student employee supervisors need to get to know and understand the cultures of their employees. They need to ask questions and interact with these individuals.

\section{Training a Diverse Student Group}

A variety of training aids is necessary when the student employee group becomes increasingly diverse. Hearing-impaired employees or individuals whose native language is not English may require different training approaches. For the supervisor, this means that flexibility in delivering information on how to do the job may be warranted. Supervisors need to keep the objectives of the training in mind and to modify delivery of the training to fit the situation. "Over-reliance on written manuals or on verbal communication will handicap some individuals. A combination of written documentation, one-on-one training, and audio or video materials contributes to successful job training."15

It is important to remember that there are differences in learning styles-some learn best through an experiential approach, others through reading and lec- 
ture. "While it seems clear that there is considerable variation among individuals concerning preferred learning styles, it also seems clear that cultures affect people's preferences for ways of learning. In the last two decades or so, many American educators and trainers have become supporters of 'experiential learning' in which students or trainees take an active part in some structured experience, which is then discussed ('processed') under the trainer's direction."16

However, such training does not necessarily have universal appeal. Yuichi Kondo studied Japanese students' negative responses to experiential learning and found their assumptions differed from those of most Americans. Some of the assumptions the students identified were:

- Trainees learn concepts and information through didactic methods; learning by doing is more appropriate for acquiring manual skills.

- The group, not the individual should be the focus of training.

- Assertive verbalization is not at all valued. Training should emphasize listening, observing, and reflecting, not speaking. Expressing a view contrary to that of another participant is particularly unseemly. - The trainer's role is that of professor or expert, not that of the facilitator. The trainer-trainee relationship should be formal.

- Hearing about other participants' personal experiences cannot be as helpful as hearing from the teacher.

- Workshop participants are not all equal. There is a status hierarchy within the group, based mainly on age, and that fact cannot be overlooked. ${ }^{17}$

Learning-disabled student employees may present other challenges that manifest themselves during training. "The learning disabled person often shows no visible characteristics of the disability; casual observers don't realize that a problem in processing information causes the person to cope differently from others."18 Some students will share their learning disability with employment supervisors. If so, supervisors should question these students about what helps them to learn and should modify their training plan accordingly. Other students will not share the information about their learning disability. Learning-disabled students may exhibit one of the following behaviors:

- Has trouble understanding or following directions; is easily overwhelmed by a multiplicity of directions or over-stimulation; may not understand the information the first time it is given and may need to have it repeated.

- Confuses similar numbers such as 3 and 8, 6 and 9 or transposes numbers (14 becomes 41, for example); has difficulty copying numbers accurately and working with numbers in columns.

- Exhibits severe difficulty in sticking to simple schedules; repeatedly forgets things, loses possessions, and generally seems 'personally disorganized.'

- Seems disoriented in time-is often late to class, unusually early for appointments, is unable to finish assignments in the standard time period or rushes to complete them not using all of the time allocated. ${ }^{19}$

If such behaviors are exhibited during training or at other times in the employment experience, it is wise to seek help from the advising or counseling office. Those who have expertise in learning disabilities can help determine the best method for the student to learn the job or to learn how to cope with things that may interfere with good work habits. 
Thiederman offers the following tips for training the immigrant and ethnic worker; such suggestions are useful for any student employee who does not share the background of the dominant group, including those with learning disabilities:

1. Do not try to cover too much material at one time.

2. Organize your thoughts, and avoid unnecessary asides.

3. Allow self-graded quizzes.

4. Avoid the use of multiple choice questions.

5. Allow questions to be asked anonymously and in writing.

6. Invite informal group leaders to participate and ask questions as a way of encouraging the others.

7. Use visual aids.

8. Use extensive handouts.

9. Speak slowly and distinctly, but do not patronize.

10. Use simple phrasing and familiar words.

11. Avoid jargon, slang, and idioms.

12. Provide a glossary of necessary jargon.

13. Do not talk too much.

14. Recap and check for understanding frequently.

15. Do not force debate and competition. $^{20}$

If the students will be working with other staff members within the department or in other departments, those staff members should be included in the training process. "For staff members who worry their cultural, ethnic, or racial background may not be readily accepted in the workplace, the chance to meet and develop good work relationships with other staff members takes on added importance." 21

\section{Supervising a Diverse Work Group}

Communication is the key to supervising a diverse work group; the supervisor will need a variety of formats and often need to communicate the same thing both orally and in writing. For example, many African Americans come from backgrounds that prefer oral over written communication, and many Native Americans, out of respect, are taught not to look directly into the eyes of those in authority when speaking. ${ }^{22}$

On most American campuses, strangers often say hello to those they pass on the sidewalk or strike up a conversation while waiting to check out a book. In an unpublished study of interactions among family housing residents at the University of Iowa, it was found that there are differing cultural assumptions regarding communication. Koreans, Japanese, and Chinese generally will not make eye contact with people they do not already know; this is usually considered rude. People from Moslem cultures might make eye contact with strangers of the same sex, but not with members of the opposite sex. ${ }^{23}$

Communication with a diverse set of student employees means that the supervisor must become aware of his or her own expectations as a supervisor and the cultural values of the students. Supervisors should consider the following: ${ }^{24}$

- What happens when they supervise someone whose culture values the group over the individual?

- Does a seeming lack of initiative mean the student does not care, or is it caused by the employee's perception of his or her place within the group?

- They encourage questions, but some cultures value harmony at all costs and frown on any kind of questioning of authority.

- How can a manager tell if he or she is being understood if employees continually nod yes but do not carry out the instructions?

- Looking an authority figure in the eye is considered highly disrespectful in some cultures; do they consider it a sign of insecurity? 
Individuals from different cultures may exhibit different communication styles. The emphasis in the communication concerning the work to be done should be on substance and clarity, not style. Some of the common communication differences the supervisor may encounter are in the following areas.

- Nonverbal signs: Nonverbal signals are not universal. Most Americans prefer eye contact to indicate understanding, but lack of eye contact is a sign of respect in many cultures. A blank expression is a way to hide emotions in the Far East; for Americans it is often a sign of not understanding.

- Questions: A lack of questions can indicate that the listener is not understanding enough to formulate a question. Questions should be invited in writing; admitting a lack of understanding in front of others sometimes is difficult. Some students need time to prepare questions; allow for overnight thinking and questions daily.

- What does yes mean?: Does it mean yes I heard you, or yes I understand? In Asia, it is appropriate to acknowledge a question with an initial yes.

- Time and spatial orientation: The issues of time perspective and spatial orientation stand out as examples of culturally determined behavioral patterns that can cause confusing experiences. Many of us do not have a relaxed attitude toward time and are very serious about deadlines and starting meetings on time. The more relaxed attitude toward time demands is evident in many cultures and gives rise to phrases such as Hawaiian Time in Hawaii and Rubber Time in Malaysia. In the Philippines, Stateside Time is a request that people be prompt. ${ }^{25}$ The way people orient themselves in space with regard to others also is culturally determined and practiced. For instance, Latin Americans typically keep much less distance between themselves during a conversation than do EuroAmericans. ${ }^{26}$

When someone does something the supervisor considers wrong or does not act the way the supervisor expects, the supervisor should take advantage of the opportunity to discuss the issue. Nine times out of ten, the reason for the mistake is that the supervisor did not communicate what he or she wanted done or how. The supervisor probably tried to communicate but did not realize that in the communication he or she was making all types of assumptions of knowl-

\section{Different cultural backgrounds influence how people think about the role of authority and power in formal communication settings.}

edge and understanding that just were not there. It is very difficult to fully appreciate how much people learn from their cultural heritage and how much from direct instruction. The biggest mistake supervisors make is to believe that every other culture has the same values and understandings that they do. When other cultures do not, the assumption is that they are wrong and we are right.

\section{Authority and Power}

The role of the supervisor and interaction between coworkers may be unclear to members of a culturally diverse work group. Different cultural backgrounds influence how people think about the role of authority and power in formal communication settings. Communication relationships within an educational setting often involve power differentials between teacher and student, student and adviser, student employee and supervisor. Americans tend to ignore or minimize the in- 


\begin{tabular}{|ll|}
\multicolumn{1}{|c|}{ TABLE 1 } \\
Mainstream America Compared to Other Cultures
\end{tabular}

fluence of power differentials on intercultural interactions because of their beliefs about equality. ${ }^{27}$ As Althen points out:

Americans also have difficulty understanding - and indeed even perceiving-power differentials among members of particular nationality groups on their campuses and in their communities. The fact that a 27-year-old Korean student expects obedience from a 26-year-old Korean student, or that a graduate of a Chinese 'key university' has more influence than a graduate of a lower-ranking institution, is easily lost on most Americans. ${ }^{28}$

Thiederman suggests that differing attitudes toward authority can affect work relationships. Table 1 depicts her comparison of mainstream America with other cultures.

\section{Individual versus the Group}

Supervising diverse student employees means dealing with different levels and types of work experience as well as associated work norms. Often individuals are unaware of the patterns that guide their behavior. Thus, when confronting a situation different from one's past experience, there is a tendency to respond and interpret it from a familiar perspective. For most Americans, identity is determined by individual achievement, not by group affiliation, which is particularly important in Japan and Mexico where family, school, and company provide status and identity. Middle Eastern, Hispanic, and Asian groups are most concerned with how mistakes will affect the group, not with how they will reflect on the individual. Many Americans value competition within a group because it promotes creativity and productivity, whereas other cultures believe that competition among group members decreases productivity and harmony. Such differences can affect work behavior and challenge one's method of supervision. Before differences create conflict between the supervisor and diverse student employees, or between them, it is good practice to learn about the culture and work norms these students have learned previously. ${ }^{29}$

\section{Evaluating a Diverse Work Force}

Providing frequent positive reinforcement for desired behavior can be very effective when it comes to motivating a culturally diverse staff. Praising behaviors that match the supervisor's expectations is one way to build a shared set of work norms regardless of the diversity composition of the work group. Depending upon the employees' backgrounds, the supervisor may need to be sensitive with regard to the appropriate way to give praise-whether to praise employees individually, address comments to the group as a whole in meetings, or extend praise through personal notes.

Communication problems can lead to misunderstanding when reviewing employee performance. "When individuals 
from varied backgrounds come together on the job, they can bring new energy and creativity. However, differences in language, norms, and values can also be the source of conflict and misunderstanding. One area of managerial responsibility, where the risk of communication impasse is great, is the performance review." 30

\section{Aware that they are not the majority, diverse employees may experience fear when being evaluated.}

The review of individual employee performance may be a new practice to culturally diverse employees used to group evaluation. In some cultures, the individual is not evaluated; seniority and family connections count more than performance. If this is the case, time should be taken to explain to the employee how the system works and why it is important. This is why it is important to discuss the evaluation process in the orientation and in the student employee handbook. If, based on past experience, the supervisor knows that a student from a particular background may have a problem with the evaluation process, he or she should spend time with that student before doing the evaluation.

It is rare to find anyone who does not approach a performance review without some anxiety. "Staff members who are not part of the dominant culture of the institution may have even more apprehensions about the performance evaluation process. . . . Think for a moment about how you might feel if you were:

- An older female employee being evaluated by your younger, male boss.

- An employee with a temporary work permit awaiting a green card, being evaluated by your American born manager.

What assumptions would you make? What expectations would you have as you approached your evaluation session?"31

\section{Explain the Purpose}

Aware that they are not the majority, diverse employees may experience fear when being evaluated. They may perceive that they have no recourse to any judgment or may fear losing their jobs. The supervisor needs to be clear about the purpose of the evaluation meeting and the fact that it is a normal practice in the workplace. He or she should explain the performance evaluation process at the orientation and, as necessary, to individuals throughout the year. This should involve explaining the reasons for the evaluation, how the student employees can benefit, and how they can help. At the performance review meeting, the supervisor should discuss what is going well and what can be improved, and set new learning goals.

In the more structured setting of an individual performance evaluation, the employee may be surprised when the task is more important than the relationship. If evaluation forms with categories and boxes are used, the form can appear more important than the person. As a way to mitigate this, Anita Rowe suggests that supervisors attempt to maintain the same tone in the evaluation session that they use in everyday activities, making sure to avoid legalese. ${ }^{32}$

\section{The Rewards of Increased Student Employee Diversity}

Increased diversity within the library's student employee staff can contribute to the university goals related to the recruitment and retention of talented and diverse students and staff. Successful employment experiences on campus may well contribute to the retention of a diverse student population as it decreases the sense of alienation, provides for the development of useful skills, and gives the student another place in the campus community.

Paying attention to hiring and managing a diverse group of student employees can be a positive challenge to old ways 
of doing things and give new insights on providing service to the whole community. Diverse student employees can serve as sources of information and contribute their perspectives about what might make the library more inclusive in the types of services offered and how they are offered. The presence of diverse student employees can create a more welcoming atmosphere for other members of the college community using the library services.
Increasing diversity adds another dimension to the task of supervision. Librarians who rise to the challenge most likely will find increased clarity in their dealings with all library staff. By respecting each employee as an individual with diverse talents to contribute, the student employee supervisor will be headed in the direction of ensuring a productive and meaningful work experience for everyone involved.

\section{Notes}

1. Rafaela Castro and Richard Chabran, "Discourse and Discord: Voices from an Academic Library," in Racial and Ethnic Diversity in Academic Libraries: Multicultural Issues, ed. Deborah A. Curry, Susan Griswold Blandy, and Lynne M. Martin (Binghamton, N.Y.: Haworth Pr., 1994), 280 .

2. Darlene M. Ziolkowksi, "Managing a Diverse Workforce," Journal of Library Administration 21 (1995): 48.

3. R. Roosevelt Thomas Jr., "The Concept of Managing Diversity," Public Manager: The New Bureaucrat 25 (winter 1996): 41-43.

4. E. J. Josey, "The Role of the Academic Library in Serving the Disadvantaged Student," Library Trends 20 (fall 1971): 432-44.

5. John Mark Tucker, "An Experiment in Bibliographic Instruction at Wabash College," College $\mathcal{E}$ Research Libraries 37 (May 1977): 203-9.

6. Barbara MacAdam and Darlene P. Nichols, "Peer Information Counseling: An Academic Library Program for Minority Students," Journal of Academic Librarianship 15 (Sept. 1989): 204-9.

7. Barbara MacAdam, "Supervising a Diverse Staff," in Cultural Diversity in Libraries, ed. Donald E. Riggs and Patricia A. Tarin (New York: Neal-Schuman, 1994), 132-33.

8. Donna Z.Pontau, "Transforming Academic Libraries for Employees and Students with Disabilities," in Diversity and Multiculturalism in Libraries, ed. Katherine Hoover Kill (Greenwich, Conn.: JAI Pr., 1994), 162.

9. Jim Kennedy and Anna Everest, "Put Diversity in Context," Personnel Journal (Sept. 1991): 53.

10. Ziolkowski, "Managing a Diverse Workforce," 57.

11. Sondra Thiederman, Bridging Cultural Barriers for Corporate Success: How to Manage the Multicultural Workforce (New York: Lexington Bks., 1991), 217-18.

12. Ziolkowksi, "Managing a Diverse Workforce," 55.

13. Ibid.

14. Gary Althen, "Cultural Differences on Campus," in Learning Across Cultures, ed. Gary Althen (NAFSA: Association of International Educators. 1994), 65.

15. MacAdam, "Supervising a Diverse Staff," 138.

16. Gary Althen, "Recurring Issues in Intercultural Communications," in Learning across Cultures, ed. Gary Althen (Washington, D.C.: Association of International Educators. 1994), 189-90.

17. Ibid.

18. Mary Lou Santovec, ed. Building Diversity: Recruitment and Retention in the '90s, 2 nd ed.

(Madison, Wisc.: Magna Publications, 1992), 95.

19. Ibid., 96.

20. Thiederman. Bridging Cultural Barriers for Corporate Success, 223-24.

21. MacAdam, "Supervising a Diverse Staff," 139.

22. Alvin C. Hill Jr. and James Scott, "Ten Strategies for Managers in a Multicultural Workforce," HR Focus 69 (Aug. 1992): 6-7.

23. Althen, "Cultural Differences on Campus," 62.

24. Heather Blenkinsopp, "Communicating across Cultures for Reference Librarians Who Supervise," in Racial and Ethnic Diversity in Academic Libraries: Multicultural Issues, ed. Deborah A. Curry, Susan Griswold Blandy, and Lynne M. Martin (Binghamton, N.Y.: Haworth Pr., 1994), 41.

25. Kenneth Cushner and Richard W. Brislin, Intercultural Interactions: A Practical Guide, 2nd ed. (Thousand Oaks, Calif.: Sage Publications, 1996), 286. 
26. Ibid., 287.

27. Althen, "Recurring Issues in Intercultural Communications," 186.

28. Ibid., 187.

29. Thiederman, Bridging Cultural Barriers for Corporate Success, 97-99.

30. Anita Rowe, "Understanding Diversity Blind Spots in the Performance Review," CUPA Journal (winter 1993): 9.

31. Ibid., 9-10.

32. Ibid., 10. 